\title{
DE NORTE A SUR: MESTRE PANTERA Y LA CAPOEIRA COMO CULTURA URBANA Y MIGRATORIA EN LA PERIFERIA DE RÍO DE JANEIRO
}

\author{
Menara Lube GUIZARDI ${ }^{1}$
}

\section{Resumen}

El presente artículo reconstruye la historia de vida de Pantera, maestro de capoeira que creció en las favelas de Río de Janeiro entre los 60 y 70. De la mano del maestro, narraremos el proceso de consolidación de la capoeira como una cultura urbana y migratoria. A través de sus sagaces desplazamientos, analizamos en qué sentido este arte articuló una comunidad que institucionaliza sentidos propios de territorialidad e historicidad sedimentados como una cultura corporal-comunitaria. Desde la memoria del maestro, ubicaremos y narraremos este proceso urbano-local brasileño que preparó jóvenes de las favelas para una verdadera "vuelta al mundo".

Palabras-clave: Capoeira, cultura urbana, migraciones, desigualdad, exclusión urbana.

\begin{abstract}
This paper reconstructs the life history of Pantera, a capoeira master raised in Rio de Janeiro's shantytowns between the 60's and 70's. As we follow Pantera's life narrative, the process of consolidation of capoeira as an urban and migratory culture will be explained. Following the mestre's displacements, I will analyze how the capoeiristas articulated a community that institutionalized a specific sense of territoriality and historicity, thus consolidating a bodily-communitarian culture. Following Pantera's memories, we will place and retell this urban-local Brazilian process that prepared young people from shantytowns to a "spin around the world".
\end{abstract}

Keywords: Capoeira, urban culture, migrations, inequality, urban exclusion.

\section{Résumé}

Cet article retrace l'histoire de la vie de Pantera, le maître du capoeira qui a grandi dans les favelas de Rio de Janeiro du 60 à 70. Dans la main du maître, raconte le processus de consolidation de la capoeira comme une culture urbaine et de l'immigration. Grâce à son mouvement intelligent, nous analysons dans quel sens cette communauté artistique qui institutionnalise articulé un sentiment de territorialité et de l'historicité comme une culturesédimentée corps-communauté. De la mémoire du maître, ce processus permettra

\footnotetext{
1 -Doctora en Antropología Social (Universidad Autónoma de Madrid, España) Centro de Estudios Avanzados Universidad de Playa Ancha. Viña del Mar, Chile. menaraguizardi@yahoo.com.br
}

Fecha de recepción del artículo: Febrero 2012

Fecha de evaluación:Mayo 2012 
de repérer et de raconter urbain local jeunes Brésiliens des favelas préparé pour une véritable «tour du monde".

Mots-clés: capoeira, la culture urbaine, la migration, l'inégalité, l'exclusion urbaine.

\section{Capoeira, espacio urbano y migraciones en Brasil}

Entre los siglos XVIII y XIX la capoeira surgió en los espacios urbanos de tres ciudades portuarias brasileñas (Soares 2002): Río de Janeiro (en la región sureste) y Salvador y Recife (en la región noreste). Practicada por esclavos africanos o afro-brasileños este género cultural complejo (Lewis 1992) -mezcla de lucha, arte marcial, baile, y músicarápidamente se convirtió en motivo de pánico entre las élites euro-brasileñas (Dias 2001; Flory 1977; Graden 1996). La aristocracia urbana y propietaria de esclavos temía la capacidad de violencia física desarrollada por los "negros-capoeira"2 y la impresionante apropiación de espacios urbanos que ellos llevaban a cabo organizados en bandos -las "maltas de capoeira" (Soares 2002)-. Más allá del recelo por las actividades criminales (hurtos, peleas callejeras, asesinatos, incentivo a la fuga de esclavos), el miedo de las élites se refería crucialmente a que este tipo de organización colectiva sugería la posibilidad de una revuelta esclava como la haitiana de 1835. En Río, donde los esclavos accedían al $73 \%$ de la población en mediados del siglo XIX (Flory 1977), las élites impulsaron un fuerte aparato de persecución de la capoeira y de todas las abundantes manifestaciones culturales urbanas de los africanos (como el lundu, la macumba, el maxixi, y el curanderismo). Esta violenta represión persistió todo el siglo XIX, criminalizando estas prácticas culturales y estampando en ellas el sello social de "pecaminosas y sucias": un obstáculo a la constitución de una sociedad civil en Brasil (Graden 1996).

En Río, capital nacional hasta 1960, la persecución a la capoeira llevó al aprisionamiento y castigo físico de los capoeiristas, suponiendo la casi desaparición de la práctica y su reclusión a las zonas periféricas - a los "morros" (cerros) - usualmente ocupados por la población. Algo muy similar acontecería en Recife, lo que limitaría la práctica urbana de la capoeira a Salvador. Esta situación permanecería así hasta 1930, cuando el proyecto populista de Getulio Vargas de constitución de una identidad nacional mestiza transformó la cultura negra en cultura nacional y otorgó a la capoeira el título de "deporte nacional brasileño" (Guizardi 2011).

Pero la reaparición de la capoeira en Río y Recife, así como su expansión hacia regiones donde era desconocida, se debe a otro fenómeno: la intensificación y masificación de las migraciones internas. A partir de 1950, la mecanización de la producción agrícola asociada a la concentración de la riqueza en las grandes ciudades industriales del sureste, provocó un éxodo rural masivo que prácticamente invirtió la distribución humana en Brasil. Si en 1950 el 63,8\% de la población vivía en el medio rural, en 1980 solamente el 32,4\% lo hacía. Se estima que, entre 1960 y 1980, 27 millones de brasileños emigraron del campo hacia las ciudades (Caramano y Abramovay 1999:2), de los cuales 18,6 millones eran provenientes de las regiones agrarias del noreste (Caramano y Abramovay 1999:9-13). En el noreste brasileño, la población emigró de las pequeñas ciudades interioranas a las grandes ciudades de la costa (como Salvador y Recife) y de ahí hacia las ciudades del sureste (fundamentalmente a Río y Sao Paulo). Esa masa poblacional desplazada al sureste generó un lumpen proletariado que alimentaria la expansión industrial y que se acumularía en numerosos bolsones de pobreza urbana. La falta de infraestructura para recibir a la población desplazada culminó en el surgimiento de asentamientos humanos en las áreas desocupadas de las grandes ciudades, consolidando la expansión de las favelas.

\footnotetext{
2 Esclavos que practicaban capoeira. Actualmente, los practicante del arte se denominan "capoeiristas".
} 
Por otro lado, este flujo poblacional hacia las ciudades del sureste llevó las múltiples "culturas regionales" hacía los espacios donde las decisiones político-económicas eran tomadas. La cultura negra que había florecido desde los años treinta como producto legítimo del noreste se expandió al sureste. En las favelas de Río, los migrantes del noreste empiezan a enseñar la capoeira a jóvenes cariocas $^{3}$, entendiendola ahora no solamente como una cultura corporal de negros urbanos, sino también como una cultura de las gentes migrantes.

Nuestro encuentro con la capoeira carioca, sin embargo, ocurrió en un espacio urbano muy distinto, situado en el otro lado del Atlántico y tiene su inicio en 2006, cuando conocimos la red de escuelas de capoeira de la Asociación de Capoeira Descendientes de Pantera (ACDP) en Madrid, España. Entre 2006 y 2011, estudiamos la ACDP y otras 20 asociaciones gestionadas por capoeiristas brasileños en España y destinadas a alumnos europeos que aprendían la cultura física de la capoeira, se socializaban a las rodas ${ }^{4}$ (en calles, plazas y parques) y se integraban a la impresionante red internacional que estos colectivos mantenían entre casi dos centenares de ciudades europeas.

Esta impresionante capacidad de adaptación al espacio urbano, de desplazamiento internacional y migratorio nos hacía indagar cómo estas redes comunitarias de la capoeira se iniciaron y cómo habían logrado salir de la favela al mundo. Para contestar estas indagaciones nos dedicamos a reconstruir la historia de vida de Mestre Pantera, el primer maestro brasileño de capoeira a emigrar a Madrid (en 1990) y a quien realizamos una serie de entrevistas entre 2007 y 2010.

Pantera fundó la ACDP en 1973 en el periférico barrio de Padre Miguel. En su impresionante navegación por el mundo de la capoeira, el maestro cruzó importantes fronteras sociales brasileñas, expandiendo su grupo de la periferia a las zonas nobles de la ciudad. Este cruce social le armó de unos conocimientos sobre la navegación social que le permitirían replicar estos "cruces" en Europa. Así, la experiencia de la capoeira que Pantera aprendió como una cultura de migrantes del noreste brasileño en las favelas de Río se convirtió en el capital social que le permitió finalmente cruzar las fronteras entre el sur y el norte global. En fines de 2010, la asociación de Pantera se encontraba distribuida entre 7 diferentes ciudades europeas, además de mantener sus actividades en tres diferentes estados brasileños.

El presente artículo reconstruye parte de la historia de vida del maestro en Río entre los 60 y 80. De la mano de Pantera, narraremos el proceso de consolidación de la capoeira como una cultura urbana y migratoria. A través de sus sagaces desplazamientos, analizamos en qué sentido la capoeira pudo constituir una comunidad que institucionaliza sentidos propios de territorialidad e historicidad sedimentados como una cultura corporalcomunitaria. Desde la memoria del maestro, ubicaremos y narraremos este proceso local brasileño que preparó jóvenes negros de la periferia para una verdadera "vuelta al mundo".

\section{Ubicarse en el pasado}

"Calle del Teniente Vitor Batista, número 176, barrio de Realengo, suburbio de Río de Janeiro". Así, con esa precisión geográfica muy suya, Carlos Alberto Moreira da Silva, Mestre Pantera, nos indica el sitio donde nació y creció. "Es todo cuestión de conocer el tiempo", dice el maestro reiterando que lo esencial en la vida (y en la capoeira) es que la

\footnotetext{
${ }^{3}$ Gentilicio de quien nace en la ciudad de Rio de Janeiro.

${ }^{4}$ La capoeira se practica en un círculo al que se denomina roda de capoeira [rueda de capoeira]. Esa rueda dibujada sobre el suelo por la disposición de capoeiristas e instrumentos musicales amolda un universo sui generis: una circularidad que se deja conocer como una representación simbólica del mundo. Darle una volta en los límites internos de la roda de capoeira es, en el lenguaje de los capoeiristas, "darle la vuelta al mundo.
} 
persona determine su posición: que conozca el área donde está parado y que circunscriba su propio tiempo.

Según Pantera, el tiempo equivale a un espacio óptimo determinado por cada capoeirista e inscrito en una distancia que se delinea a partir de la separación de los dos pies apoyados paralelos sobre el suelo. Cuanto más separados los pies, mayor el tiempo y viceversa. Dentro de los límites de esa separación, el sujeto debe ejecutar cualquier movimiento (y secuencia de movimiento) en cualquier velocidad. Además de variar de persona para persona, el tiempo también varia en una misma persona de acuerdo con el nivel de perfeccionamiento de la técnica de la capoeira. En la medida en que adquieren experiencia, los alumnos lograrán dominar la ejecución de los movimientos con diferentes matices de fuerza, amplitud, velocidad e intensidad, adaptándolos a dimensiones cada vez menores. Uno de los objetivos del entrenamiento del capoeirista es justamente permitirle ejecutar los movimientos en diferentes tiempos, improvisando de acuerdo con el contexto del juego.

Así, la temporalidad de la capoeira es una función de la capacidad de adaptación de los movimientos en el espacio (y con el espacio), pero también es una función a ser adecuada a las circunstancias: improvisada, transgredida, alterada por el sujeto en su relación con el otro jugador, un tiempo que existe debido al movimiento del cuerpo. En los discursos de capoeiristas como Pantera, esa noción temporal se conforma como un referente de acción que les ubica, más allá del espacio de la roda, en las relaciones sociales ampliamente comprendidas. El tiempo corporal-espacial-dialógico de la capoeira es un valor relacional vivido por los capoeiristas en sus desplazamientos migratorios por el mundo.

Es cierto que los capoeiristas suelen empezar sus conversaciones narrando historias e invocando al pasado (Bruhns 2000:23), pero en el caso de Pantera, esos relatos son enfáticamente situados en el espacio, y quizás por eso sus narraciones nos transmiten la impresión de que todo viaje en el tiempo es también un viaje a otros espacios, un movimiento que solo puede tener sentido desde el punto de vista del desplazamiento de la gente y de las situaciones recordadas. Y así, sin pretenderlo o sin ver en ello nada extraordinario, el Mestre presenta una memoria abiertamente planteada como un proceso de selectividad que ubica e integra, que construye el pasado a partir de sus localizaciones algo muy cercano a lo que Fabian (2007:107) entendió como la memoria desde una perspectiva antropológica, siempre atenta al descubrimiento de que un presente común implica ser capaz de recordar un pasado común.

El papel estructurante de la ubicación y del desplazamiento en el espacio es la razón por la que la historia de vida que Pantera nos contó una y otra vez, siempre se hizo acompañar de la curiosa alusión a los nombres de las calles, a los números de las casas, a las descripciones de los barrios. Detalles que nos permiten dar sentido a los movimientos que el maestro vivió hasta emigrar a España: a los desplazamientos de su tiempo que son a la vez desplazamientos sociales. Nuestra mirada etnográfica asumió la mirada del capoeirista e incorporó como suya la importancia de entender el tiempo y el espacio de uno, y de dar un sentido inherentemente político a todo desplazamiento.

Ese sentido político del desplazamiento se vincula a dos factores. En primer lugar a la propia dimensión política del espacio en el Río de los años 60. Las desigualdades económicas y sociales de la sociedad carioca son, antes que nada, realidades espaciales, fuertemente vinculadas a una grafía territorial que es el ser y el estar de las estratificaciones sociales. Y si el sentido de pertenecer al centro de la sociedad o a sus márgenes encuentra en el espacio una metáfora que le da materialidad, entonces cruzar el territorio urbano es, indeleblemente, cruzar las fronteras políticas que definen quienes pertenecen a qué espacios. En segundo lugar, los desplazamientos contados por Pantera son políticos porque son frutos de su esfuerzo por rememorar. El acto de recordar fija y mueve la historia a partir de la posición del narrador, construye una versión de los hechos elaborada desde el sujeto y que, dentro de algunos límites, presenta una forma 
contestataria de relato sobre el pasado. Si toda memoria es recordada, entonces toda memoria es, en algún sentido, política (Fabian 2007:94).

\section{Ser de Realengo, ser de la Zona Norte}

Pantera nació y creció en Realengo, una vecindad de clase media baja que surgió oficialmente en 1815 en unas tierras pertenecientes a los reyes de Portugal (Viana 2010). Casi todos los barrios y favelas de la Zona Oeste de Río (como Realengo) fueron construidos sobre antiguos latifundios azucareros abandonados por las familias aristocráticas decadentes e invadidas por la gente pobre. También es cierto que esos barrios recibieron a los africanos despojados de las haciendas después de la abolición del trabajo esclavo en 1888, lo que asentó en el área una población mayoritariamente afrodescendiente. En la segunda mitad del siglo XIX, la región recibió instalaciones militares: la Escuela Militar de Tiros del Campo Grande (1859), la Fábrica de Municiones (1898) y la Escuela Militar de Formación de Oficiales (1913) son ejemplos de la presencia estructurante del ejército en la localidad. Además de impactar la manera como la comunidad se distribuía e interaccionaba (Viana 2010), la presencia militar influenció los imaginarios de la juventud local, lo que nos viene a ser muy relevante a la hora de explicar la "naturalidad" con que Pantera y otros capoeiristas entendían su obligación de servir al ejército. En la dictadura militar (1964-1986), el barrio abrigó además la penitenciaria donde eran encarcelados artistas "subversivos" e intelectuales disidentes del régimen (Faria 2005:8).

Pese a la ampliamente distendida presencia del ejército, es cierto que el barrio de Pantera permanecería rural y bucólico hasta mediados de los setenta (Paz 1987:10), cuando las migraciones masivas (Perlman 2008:228), el empobrecimiento y la expansión urbana (Leeds y Leeds 1978: 105-106; Perlman 2002:3) involucrarían las zonas agrarias del oeste carioca en las dinámicas urbanas del centro, convirtiéndolas en el espacio de vivienda de la abundante mano de obra empleada en los distritos "más desarrollados". En un muy corto período de tiempo, Realengo sufriría una abrupta modificación que lo convertiría de zona agraria a zona militar, residencial e industrial (Viana 2010). La existencia de edificios militares (un enclave del orden social hegemónico en una localidad periférica) es subvertida por la ocupación (invasión) de las tierras por la población pobre. Esa tensión entre los socialmente marginados y los socialmente centralizadores resultará en la victoria de los primeros: progresivamente, las instalaciones del ejército van siendo desactivadas o transferidas a otros distritos. En la niñez de Pantera, sin embargo, la influencia militar impregnaba el sentido de futuro de los jóvenes que allí crecían.

Así, Realengo es un locus intersticial: puesto entre el lugar marginal de la población pobre (en su mayoría afro-descendente) y el lugar institucional de la violencia política del Estado brasileño. El primer maestro brasileño emigrado a España nació en un área conectada, culturalmente con la condición marginal de los negros y estructuralmente con la nueva pobreza urbana que dibujaría los contornos de las metrópolis brasileñas en el siglo XX (Santos 2008:116-117) ${ }^{5}$. Pantera es un hombre negro del suburbio, que creció rodeado de favelas, cercado por la improvisación, por el esfuerzo de supervivencia. Pero al mismo tiempo su barrio se conformaba como una "zona límite", compartiendo su marginalidad social con la presencia centralizadora de la autoridad militar y negociando con esta última algunos términos de coexistencia. Pantera, como muchos capoeiristas de su generación, viene de un universo donde la vida cotidiana requiere dinámicas constantes de mediación simbólica-relacional. Ese es el contexto en que tiene origen -como un movimiento llevado

\footnotetext{
${ }^{5}$ La introducción del capitalismo industrial en Brasil a partir de 1940 impulsa la urbanización de la nación y el empobrecimiento popular, un modelo económico de: "gran crecimiento, basado en un considerable desarrollo material, y, como contrapunto, en el campo social y político, un desarrollo negativo, llevando al surgimiento de una clase media relativamente numerosa y de una extrema pobreza" (Santos, 2008:117).
} 
a cabo por jóvenes pobres y mayoritariamente negros- la asociación de capoeira que encontraríamos diseminada entre siete ciudades europeas.

Nuestra tarea de ubicar a Pantera en su "tiempo" no estaría completa si no considerásemos un detalle semántico imprescindible: para el imaginario colectivo carioca, la pobreza está fuertemente asociada a lo que se entiende como la "Zona Norte" de la ciudad, mientras la riqueza, se asocia a la "Zona Sur". Esta espacialización de las desigualdades sociales en Río se refleja en el IDH de los diferentes barrios:

El nivel de desigualdad de Río (el índice Gini municipal es 0,616) es peor que el de Brasil en general $(0,593)$. Además, la brecha entre pobreza y prosperidad en la 'ciudad maravillosa' aumentó durante la década de 1990 (IPP, 2005). Esto ha dado como resultado calificaciones muy diferentes para distintas partes de la ciudad, según el Índice de Desarrollo Humano (IDH) del Programa de las Naciones Unidas para el desarrollo. El barrio de 'Gávea' en la zona sur de la ciudad disfruta de una calidad de vida comparable a la de Bélgica, que se clasifica novena en el IDH. Sin embargo, el 'Complexo do Alemão' en la zona norte de Río tiene una calidad de vida cercana a la de Vietnam, que ocupa el puesto 108”. (Perlman 2008:234).

Pero el "norte" y el "sur", tal como los utilizan la gente de Río, son categorías sociales que no equivalen a los puntos cardinales de la cartografía moderna. Cualquier barrio considerado pobre o marginado será un barrio de la "Zona Norte", aún cuando se localice en aquello que la administración pública denomina "Zona Oeste": "la gente de la periferia, de la favela, del suburbio, es la gente de la Zona Norte" (Pantera. Madrid, diciembre 2009). La expresión "Zona Norte" se constituye bajo un proceso de indexación simbólica (Lewis 1992) en el que un signo, ícono o símbolo asume metonímicamente el sentido atribuido a otros signos, reemplazando estos últimos en el proceso comunicativo. En el habla popular, el "norte" de la ciudad es un índex que equivale (sustituye o evoca) a la situación de pobreza, a la condición marginada, a la precarización de la vivienda y, no en pocas circunstancias, la condición de ser "negro" o afro-brasileño. Por otro lado, es importante considerar que la condición de "pobre", "marginado" y del "norte" implica una identidad social generadora de reconocimiento mutuo entre las gentes que, ubicadas en esos diferentes barrios pobres, se vinculan a un mismo emplazamiento social.

\section{Las hermanas, las abuelas y la capoeira en la calle}

Doña Vitalina, madre de Mestre Pantera, nació en el estado de Bahía (noreste brasileño). En la capital, Salvador, se casó por primera vez y tuvo dos hijos hombres (Jorge y Orlando). Vivía en el barrio de Brotas cuando su marido murió, dejándole la tarea de educar y mantener a los muchachos. La misión era imposible en una ciudad empobrecida como Salvador y por ello Doña Vitalina emigró al sureste del país, donde unos parientes fueron probar la suerte años antes. Llegando a Río encontró trabajo como empleada doméstica en un barrio de la Zona Sur en el que permanecería muchos años, educando y criando a los hijos de sus empleadores, mientras sus hijos se criaban solos por las calles de Realengo.

Fue en Río que Doña Vitalina conoció al padre de Pantera, un descendiente de ex esclavos angolanos que trabajaba en la Marina Brasileña. Con esta persona tuvo dos hijos más. La primera fue Emídia y el segundo, diez años más tarde, fue Carlos (Pantera). La crianza del joven Pantera quedaría a cargo de su hermana: "mi hermana es como mi madre porque mi madre trabajaba", resume el maestro. Emídia y él encontrarían pocas veces a un padre con quién nunca llegarían a convivir:

No. Yo no le conocí. Es que él no vivía allí [no compartía vivienda]. Él iba allá, se quedaba un fin de semana y se iba. Después que yo nací, él no fue más. Porque él viajaba mucho también. Hasta que un día, yo fui a comprar pan, jun sol caliente!, en la calle 
donde yo vivía, en la calle del Teniente Vítor Batista, en el número 176. Entonces, yo me estaba fijando en que había un hombre hablando solo. Yo iba a cruzar la calle con miedo, yo era moleque [muchacho]... entonces el hombre me llamó: 'oye muchacho, muchacho. ¡Vente aquí! ¿Tú sabes donde vive Doña Vitalina?'. Yo le dije: 'Allí, en el número 176'. Y me fui para la panadería. Cuando yo regresé, él estaba allá sentado y conversando. Entonces mi madre dijo: 'ese es tu padre'. Y él dijo: ‘¡yo le pregunté donde tu vivías!'. Zezinho... Él me llamaba Zezinho, entonces mi madre decía: ‘ ¡No se llama Zezinho! ¡Se llama Carlinhos!'. Porque Zezinho era el otro hijo que él tenía en Caxias, por allí, cerca de São João de Miriti. (...) Él hablaba de manera extraña y yo y mi hermana nos reíamos. Nos reíamos, nos moríamos de la risa y yo decía: ‘ese es mi padre? ¡No, ese no es!'. (Pantera. Madrid, enero/2010).

La familia de Pantera era comandada por la figura femenina. Su madre trabajaba muchas horas diarias para garantizarles a sus hijos unas condiciones mínimas de sobrevivencia: la explotación laboral se traducía, finalmente, en ausencia materna. De ahí que los niños quedasen a cargo de una hermana mayor, de una abuela y de "la calle", las tres figuras femeninas que usualmente "educan" las nuevas generaciones en la favela (Goldestein 2009:234).

Como la crianza de los hijos está asociada a la figura femenina en Brasil, la movilidad familiar emprendida por los hombres no tiene su equivalente en el mundo femenino. La desintegración de las parejas, en el marco de ese contexto socioeconómico más amplio, implica la permanencia de la mujer como jefa del hogar. Esta situación también se debe a que los hombres no-escolarizados encuentren más dificultad para encontrar trabajo, mientras se mantiene un nicho laboral permanente a las mujeres no-escolarizadas: los servicios domésticos. En períodos de crisis, cuando el empleo masculino no-cualificado en el sector secundario se ve amenazado, la figura femenina es la que mantiene la certeza de algún ingreso económico. Paulatinamente, las mujeres adquirieron un papel central que sobrepasa con diferencia ese rol económico: la responsabilidad de aportar equilibrio emocional en un contexto caracterizado por la institucionalización de la violencia como lenguaje social (Goldenstein 2009:227). Lo que nos resulta fundamental en este contexto es la postura de Pantera, para quien la figura paterna resultaba desconocida, ajena, difícil de asimilar.

Pantera conoció la capoeira poco antes de los ocho años de edad, cuando se presentó en Realengo un maestro emigrado de la región centro-oeste de Brasil: Tatú ${ }^{6}$. Fue en una tarde como otra cualquiera, en la que los niños jugaban a la peonza en la calle después de salir del colegio:

Y entonces, un día, estábamos sentados en la acera, jugando a las bolitas o a la peonza, y llegó el Mestre Tatú con cuatro alumnos suyos, todos moleques [muchachos] también, y nos preguntó si queríamos aprender la capoeira. Yo creo que él quería formar un grupo, ¿no? Yo ni siquiera sabía el nombre de su grupo. Entonces él nos dijo que iba a dar clases en el colegio, en la cancha, era la Escuela Ramires Galvão, que era donde yo estudiaba. Y nosotros fuimos, seguimos Mestre Tatú y empezamos a entrenar imitando los movimientos. ${ }^{\top}$ (Mestre Pantera. Madrid, enero/2010).

\footnotetext{
${ }^{6}$ La capoeira viajó a la región central brasileña de la mano de los trabajadores no-cualificados emigrados del noreste del país (empleados en la construcción de Brasilia). Mestre Tatú conoció la capoeira así: como una cultura migratoria transmitida por migrantes provenientes del noreste.

${ }^{7}$ Es común que los muchachos y muchachas de las favelas pasen toda la tarde en la calle jugando y esperando a que sus madres regresen del trabajo. Las madres a su vez, tienen poco o ninguno conocimiento de las cosas con las que esos jóvenes se involucran en su ausencia. Doña Vitalina solo descubrió que su hijo practicaba capoeira cuando este tenía diecisiete años (pese a que Pantera frecuentase las clases todos los días de la semana, sábados y domingo incluidos).
} 
Tatú también se había trasladado al sureste en busca de empleo. Había conseguido que se cediera un espacio en la escuela municipal para las clases, algo que diez años antes hubiese sido poco menos que impensable. Ese uso de un centro oficial de enseñanza indica un cierto nivel de aceptación de la capoeira en el marco de la educación de los jóvenes, y nos permite visualizar el momento en que el proceso de descriminalización de la práctica iniciado en 1930 (Bruhns 2000:24) - empezaba a abrir a los capoeiristas las puertas de nuevos locus sociales, permitiendo la transformación (lenta pero segura) del imaginario vinculado a la práctica. Personajes como Tatú eran cada vez más frecuentes en las áreas periféricas de Río y su influencia ayudó a transferir al sureste el nuevo trópos social que la capoeira disfrutó primeramente en otras localidades, especialmente en Salvador (Assunção 2005:171). Consecuentemente, la enseñanza de la cultura corporal de la capoeira, de los valores, de la vinculación carismática a los maestros y el respeto a su conocimiento fue popularizando la práctica y asociándola a una cultura migratoria; una cultura de rememoración de las raíces en una condición de desplazamiento -desplazamiento debido a la inmigración y a la experiencia de una condición social marginal-.

La vinculación de la capoeira a una "cultura del desplazamiento" se estampaba en el ejemplo vivo de los maestros que cruzaban Brasil del noreste al sureste. Esos capoeiristas divulgarían dos importantes lecciones que cambiarían la vida de diversas generaciones de discípulos cariocas: la percepción de la libertad migratoria como un valor positivo a ser apropiado por los sujetos, y la presentación de la capoeira como inequívocamente conectada a ese movimiento subjetivo de "toma de decisión", de "asunción del desplazamiento". Ese código de valores acerca del desplazamiento colinda con los patrones de conducta relativos a la capacidad de aprovecharse de las oportunidades, de improvisar en situaciones adversas, de buscar salidas que no necesariamente concuerdan con las reglas sociales. Un conjunto de valores de acción que Pantera repite a sus discípulos en Madrid: "Un capoeirista tiene que ser descarado. (...) No puede tener vergüenza, tiene que ser abierto, estar listo a todo momento, saber entrar por la puerta y por la ventana". (Pantera. Madrid, noviembre/2007).

En gran medida, los muchos maestros emigrados al sureste brasileño en los años 60 estaban entrando en el mundo "desarrollado" de Brasil por la ventana, haciendo uso de esa soltura que caracteriza al capoeirista para driblar las puertas cerradas y apropiarse de su propio destino social.

Pantera entrenaría con Tatú durante casi un año, hasta que éste decidiera regresar a la región centro-oeste. Un mes después que Tatú se fuera, la hermana mayor de Pantera descrubre que había otro maestro impartiendo clases en el vecino barrio de Padre Miguel. Era Jorge Francisco Ferreira, Mestre Poeira, y que, de la misma manera que la madre de Pantera, emigró de Salvador hacia la "Favela do Vintém" (entre Realengo y Padre Miguel):

Fue mi hermana quien descubrió eso. Entonces ella me dijo: ‘ ¡ah! Ya sé donde hay clases de capoeira. Es en Padre Miguel'. Yo no tenía ni idea de donde estaba Padre Miguel (...). Ella se informó y me llevó allá un sábado. Un sábado a las cinco de la tarde. Ella me llevó y habló con Mestre Poeira que yo estaba jugando capoeira, jugando porque en aquél entonces no se decía entrenar capoeira, se decía jugar capoeira, ella dijo que yo estaba jugando capoeira y que quería continuar. Él dijo: ponle allí en la fila. (Pantera. Madrid, noviembre/2007).

Las clases de Poeira eran realizadas en un centro comunitario gestionado por la asociación de vecinos y destinada a actividades culturales. Allí también se daban las clases de danza y se realizaban los "Bailes Black" (fiestas donde se bailaba el soul norte-americano). En este contexto de incipiente movilización alrededor de la identidad negra, la capoeira empezó a adquirir un carácter que la vinculaba a la negritud y a la guetización urbana de la población afro-descendiente. 


\section{Mestre Poeira: el barco que sabe flotar}

Mestre Poeira es el padre de capoeira de Pantera y el "abuelo" de todos los alumnos de este último. Poeira fue quién le enseñó a Pantera el arte y las malicias de la capoeira y le otorgó el título de maestro cuando este tenía dieciocho años. Poeira fue quién le "bautizó", concediéndole su mitológico apodo:

Entonces, cuando yo empecé a entrenar capoeira con mi mestre [Poeira], yo no tenía apodo. Entonces, el nombre de su grupo era Grupo de Capoeira Pantera y él me puso el apodo 'Pantera'. Dijo que yo saltaba mucho, que era una Pantera, y me puso ese mote. Yo le pedí que no cambiara más el nombre del grupo porque yo quería hacer mi historia dentro de ese mundo, dentro del mundo de la capoeira. (Mestre Pantera. Madrid, noviembre/2007).

Como todos los maestros de aquél tiempo, Poeira tenía una vida doble. Durante el día, el trabajo no-cualificado y mal pagado y durante las tardes, la labor como Mestre en Padre Miguel. En todos sus momentos libres, vivía rodeado de alumnos: "no había un fin de semana en que no golpeásemos su puerta para que él nos llevara a algún sitio, para que nos enseñara algo", dice Pantera, refiriéndose a un vínculo que extrapola en mucho el nexo racionalizado que se establece en la moderna relación profesor-alumno (Abib 2006:87) ${ }^{8}$ :

Cuando yo iba a la casa de mi maestro, y le llamaba para entrenar, yo y los otros, le despertábamos... Él sacaba el pie fuera [de casa] para decirnos que estaba despierto, y volvía a dormir. Entonces nosotros gritábamos: ‘¡Mestre, mestre! Mestre Poeira!'. En unos minutos él salía y decía: ‘uustedes me están despertando? Ahora yo tengo que ir a la panadería'. Y nosotros decíamos: ‘¡no, no, vamos nosotros y compramos el pan!’. Íbamos y regresábamos en un segundo: 'ustedes son muy rápidos. Entren y monten los berimbaus'. Entonces nosotros comíamos el pan y tomábamos café tocando berimbau. Y él vive dentro de una favela, de una favela peligrosísima. (...) Él nos escuchaba tocando 'biribim, biribim' [sonido del berimbau] y aquello animaba a nosotros mismos. Y él tomando el café se animaba con nosotros también. Cuando salíamos a la calle, él nos decía: 'mira, tú estabas tocando así, tú estabas tocando de tal manera', nos decía qué cosas teníamos que mejorar. (Pantera. Madrid, mayo/2008).

El contacto mantenido entre discípulos y maestros de capoeira en los barrios marginales como la Favela do Vintém donde aún vive Poeira - servían como la base de relaciones sociales fundamentadas en la confianza, en un tipo específico de respeto (el cimiento del liderazgo legítimo de los mestres) construido en una dinámica cotidiana de interacciones que iban del espacio privado al público y del público al privado: de la casa del maestro a la calle y de la calle a la casa del maestro. Recordando esos gratos momentos, Pantera, nos explica que jugaban con el maestro todos los días, "de lunes a lunes" y que "si pasásemos un día sin jugar capoeira, nos quedábamos locos". Ese compromiso diario con el Mestre generaba un sentido de "familia alternativa": una referencia que suplía la ausencia paterna y re-significaba el "estar en la calle":

Para el alumno es eso, ¿no? El mestre es el padre. Es porque en Brasil, la gente de la periferia, de la favela, del suburbio, de la Zona Norte, casi no convive con el padre. (...) Porque el padre se va, no convive con la madre, y es muy difícil. Entonces el alumno se inspira en el mestre, porque el mestre está siempre allí hablando: 'no, eso está mal joven, tu no debes hacer así. No, tú debes hacer así, tú tienes que ir caminando así. Tú estás gingando mal, levanta más el brazo'. Entonces tu tomas aquello como: 'ese es mi padre

\footnotetext{
${ }^{8}$ Travassos (2004:167) observó la misma relación en su etnografía sobre Mestre Muca, capoeirista carioca y discípulo de Mestre Poeira en los años 80.
} 
que me está colocando correcto en el mundo'. Y los mestres dicen: 'tú no debes fumar'. Es muy difícil que un maestro de capoeira mande un alumno fumar. La primera cosa que él hace es quitar los vicios. Entonces él va dando orientación. (...). Entonces nosotros, los mestres, ponemos eso. Un alumno no va a gritar con un mestre (...). Nosotros ponemos eso y ellos nos miran como a un padre. (...) Y nosotros vamos educando a nuestra manera. Yo ya di dinero para alumnos, para muchos que no podrían irse a casa. Alumnos que no podían pagarse las clases, yo les daba la ropa, les daba todo, pagaba el transporte para que fueran a entrenar. Y todo eso acontece en el mundo, ¿no? (Pantera. Madrid, enero/2010).

Nótese que las correcciones corporales que hacen los maestros ("estás gingando mal, levanta más el brazo") se enuncian (y son comprendidas) como consejos para la vida y no solamente para la roda ("ese es mi padre que me está colocando correcto en el mundo"). Hablando de las gingas $^{9}$, esquivas, del caminar y de los golpes, los maestros hablan también de cómo crecer en una sociedad desigual, pobre y "especialmente violenta para con los hombres jóvenes" (Goldenstein 2009:227). La experiencia corporal de la capoeira es, en ese contexto, indisociable de la experiencia de marginación social e implica la incorporación de una sabiduría societaria de solidaridad inclusiva. Educando al cuerpo de los moleques, el maestro les preparaba para la difícil tarea de encontrar su equilibrio en la sociedad brasileña. Años más tarde, esa misma moraleja sería explicada por Poeira a los alumnos europeos de Pantera:

Un día, en Palma de Mallorca, en la plaza, delante de la catedral (...), Mestre Poeira se paró para dar una charla a los alumnos [europeos]. Y le preguntaron así: Mestre, para usted, ¿qué es la capoeira? Él, en el mismo momento, miró al puerto que estaba allí delante, miró un barco y habló: 'la capoeira tiene que ver con nosotros. Con nuestra forma de caminar, con la forma de sentar, con el viento que viene trayendo la poeira [el polvo], con un barco en el mar. Un barco en el mar está flotando, ¿no? Entonces él consiguió no hundirse, entonces el barco es capoeira. Él es una cosa ligera en la vida'. Mestre Poeira siempre te contesta así, dentro del tiempo. (Pantera. Madrid, enero/2010).

El barco flota para no hundirse, igual que el capoeirista juega (y "ginga") para sobrevivir. Esta es la lección con la que Poeira educó a sus discípulos y con la que Pantera educaría sus alumnos brasileños y europeos: la capoeira es todo aquello que permite vivir de manera ligera, equilibrándose tal cual el barco que flota sobre el movimiento de las aguas. $\mathrm{Y}$ es gracias a su gran conocimiento sobre esta navegación social, que el mestre puede contestar siempre dentro del tiempo: Poeira sabe donde está parado; sabe situarse en el contexto, sabe aprovecharse de las circunstancias. Aquí, el "estar en el tiempo" se establece una vez más como piedra angular de la sociabilidad de los capoeiristas: conocer el tiempo implica saber flotar aún cuando el mar esté revuelto, saber involucrarse con la situación social específica en que uno se encuentra. La capoeira de la niñez de Pantera, la capoeira de la Zona Norte de Río en los 60, constituía un conjunto de "conocimientos corporales" que, desde el universo ritual de la rueda, habilitaba a los sujetos para sobrevivir adaptándose a la imprevisibilidad del contexto. Una experiencia societaria que empoderaba los sujetos haciéndolos dialogar con las restricciones que la sociedad brasileña dibujaba en sus cuerpos. Dicho de otra manera, la capoeira de Poeira constituía una técnica del cuerpo con un fuerte sentido de resistencia social.

Por "técnica del cuerpo" comprendemos el conjunto de habilidades corporales sedimentadas histórica y contextualmente a partir de múltiples experiencias sociales que generan usos comunes del cuerpo. Al mismo tiempo en que ellas inscriben la vida social-

\footnotetext{
${ }^{9}$ La ginga es el movimiento estructurante del juego de capoeira. Sirve para equilibrar el cuerpo del jugador mientras este se adapta al contexto (Lewis, 1992; Stephens y Delamont, 2006), es el conector usado para intercalar los "golpes", para entrar en sincronía con el tiempo y el ritmo del otro (Lewis, 1992, 1995, 1999; Merrell, 2005).
} 
comunitaria en los sujetos, también son parte de aquello que los inventa como seres sociales (Mauss 1979a). Entendemos que esas técnicas dejan un espacio para la invención, creatividad y transformación, y que extrapolan las estructuras logo-céntricas del entendimiento. Con Comaroff y Comarrof (1992) asumimos que la centralización política implica la imposición de determinadas técnicas del cuerpo con la finalidad de controlar la experiencia individual. La capoeira en el contexto de las favelas es un ejemplo de técnica corporal contestataria nacida en oposición a este intento de control: una técnica apropiada doblemente como mecanismo de resistencia al orden y como mecanismo de acomodación a la inestabilidad de una vida socialmente marginada.

Para entender la afirmación anterior, es imprescindible considerar además que los jóvenes discípulos de Poeira en Padre Miguel crecieron en un entorno social crecientemente racista, con índices alarmantes de violencia - ocasionada no solamente por el surgimiento de los grandes comandos de narcotráfico (Perlman 2008:226), como también por la "severa depresión del mercado laboral" ocurrida a partir de 1964 (Leed y Leeds 1978:105) ${ }^{10}$. Crecieron en un contexto marcado por la desagregación de los valores societarios de miles de inmigrantes provenientes de zonas rurales, y de recrudecimiento de los valores dictatoriales de una sociedad cada vez más desigual y menos democrática. Para estos jóvenes, la capoeira era un arma social a partir del cual posicionarse en el mundo y la misión de los maestros era un trabajo vocacional:

Yo nunca pagué. Ni con el Mestre Tatú, que no cobraba, ni con Poeira tampoco. El Mestre Poeira siempre dio clase en la periferia, para la gente de la favela, para la gente pobre. Él desarrollaba un trabajo social con la gente. (Pantera. Madrid, noviembre/2007).

La capoeira era gratis y era para todos. El mestre estaba presente en la vida de los moleques todos los días, con paciencia y siempre dispuesto a escuchar, con historias del pasado, y con un "algo más" que cambiaría la vida de esos moleques: el respeto. Pero ser capoeirista en los años sesenta también conllevaba hacer parte de una amplia comunidad formada por grupos de diversas favelas. Implicaba conocer las disputas y tomar partido en ellas; conocer a los maestros importantes y respetarles según las reglas; desarrollar la malicia de los movimientos con suficiente destreza para ser capaz de huir de los constantes desafíos preservando intacta la "dignidad de capoeirista". Implicaba, finalmente, convertirse en alguien suficientemente sagaz para driblar los problemas de la vida, a la manera como se dribla a otro capoeirista en la rueda. En la capoeira de esos sujetos marginales, encontramos una metáfora que:

Expresa el modo como las clases populares pueden invertir, a su favor, la fuerza visible explícita de los poderosos, evitando el enfrentamiento directo que siempre se realiza a partir de las reglas de un juego político que no fueron definidas por ellas. (Reis apud Bruhns 2000:142).

Esa poderosa imagen de empoderamiento social a partir de una subversión corporal (y los capoeiristas hablan de la capoeira como "liberación del cuerpo") es lo que va catalizando la atención de los jóvenes de áreas pobres. Practicar capoeira se convierte en una puerta de acceso a una identidad social alternativa que les une en ese movimiento de reinterpretación de su papel en la historia, de su ubicación en la sociedad, de su tiempo. Sobre eso me comentaba Mestre Tubarão, discípulos de Pantera entre los 70 y 80 :

\footnotetext{
${ }^{10}$ A partir del golpe militar de 64: "las formas esporádicas y no profesionalizadas de trabajo fueron las más duramente afectadas (...). Hubo un aumento de las tasas de criminalidad en todo Río [de Janeiro] para todos los tipos de crimen, especialmente aquellos que son cometidos por un individuo actuando solo y bajo presión: robos, asaltos, palizas, robos con asesinato. Otros mendingan, viven de la caridad vegetan de algún modo." (Leeds y Leeds 1978:105).
} 
Es lo que te digo: si no fuese la capoeira, yo no sé si estaría vivo [el entrevistado llora]. Está claro que uno hace locuras de adolescente, pero yo no me dejé envolver con el narcotráfico, con la delincuencia. Yo creí; creí en la capoeira y fue la capoeira que me hizo conocer otras personas, reconocer que yo tengo valor, independiente de haber nacido en una favela, de no tener estudios universitarios [lloro]. ¡Fue la capoeira! Entonces yo veo, y creo que las personas ven, la capoeira de forma diferente: como un vínculo vivo de una corriente de rescate cultural que no se puede dejar morir, ¿sabes? Es una misión que uno tiene [lloro]. (Tubarão. Alcalá de Henares, febrero/2008).

Alrededor de la identidad de capoeirista, conectada a ese sentido de "transmisión de un legado cultural", se va estructurando una comunidad más amplia, compuesta por centenas de identidades locales -desarrolladas a partir de la conexión con maestros de una u otra zona de la ciudad-. Discípulos de un mismo Mestre serán comprendidos como partes de una misma familia y las redes de solidaridad que se van tejiendo y destejiendo -siempre mediadas por las incesantes disputas- ganan vida a partir de la figura centralizadora del maestro. El sentido de reciprocidad existente entre aquellos que se reconocen como "capoeiristas" facilita que favores, contactos y ayudas multipliquen los vínculos, pues cada una de esas contribuciones es comprendida como un "don" (Mauss 1979b) a ser correspondido según un principio reciproco de intercambio.

Todo ese proceso de creación de una "comunidad" diseminada por las diferentes favelas se extendería entre los años 60 y 70, socializando los jóvenes capoeiristas que en las décadas de 80 y 90 promoverían dos desplazamientos fundamentales para la práctica afrobrasileña: hacia la Zona Sur de Río, y hacia el norte del globo. Durante nuestro trabajo de campo en España, observamos que esa red de relaciones entre agrupaciones se convirtió en un elemento fundamental para la adaptación migratoria de los capoeiristas. Las amistades, enemistades, alianzas entre maestros y la experiencia común de la vida comunitaria permitieron que los capoeiristas se "reconociesen" en el contexto migratorio: las redes locales de la capoeira se convirtieron en redes transnacionales que diseñaron su inserción en Europa.

\section{6 "Capoeira-camuflada": la territorialidad en los márgenes}

La apropiación del espacio público de las favelas por la capoeira -su operación como icono de una identidad negra y marginal, su presencia en centros comunitarios locales, su transmisión a los jóvenes, la realización de ruedas en las plazas, y ferias de calle- se fue haciendo con mucho cuidado, con una gran dosis de desconfianza por parte de los maestros:

(...) Él [Mestre Poeira] todos los años cambiaba el nombre del grupo. Él nos decía que la capoeira, como era muy 'camuflada' en aquellos años, uno tenía que estar siempre cambiando el nombre del grupo. (...) La persecución era más por el pasado de la capoeira de...de...de...Vamos a decirlo así, de persecución policial. Como era un poco camuflada, el grupo no podría tener mucha fama. (Pantera. Madrid, noviembre/2007).

Se temía que la policía les señalara como se solía hacer en el pasado con los bandos de capoeiristas, lo que seguramente daría inicio a una persecución y a la asociación indebida de los integrantes con la delincuencia (ambos indeseables para sujetos que luchaban por sobrevivir al estigma de marginalidad social). Pero, por otro lado, el "camuflaje" de los capoeiristas también era fruto de las disputas territoriales entabladas entre los maestros y agrupamientos que estos lideraban.

Según cuenta Pantera, en su adolescencia, los gremios de capoeiristas de las favelas cariocas competían por ganarse la fama popular de "tener la mejor capoeira", de exhibir la "capoeira más valiente". La cultura física del juego enfatizaba la masculinidad entendida como la capacidad de apropiación del poder de violencia contra el otro. La capoeira más 
dura, más peleona, la más maliciosa, era la que se llevaba la fama de "buena capoeira", de "capoeira valiente". Frecuentemente, esas disputas tenían lugar en las "visitas" que los maestros y sus discípulos hacían a las clases y ruedas de otro grupo:

Si se diseminaba la fama de que 'el grupo de Mestre Poeira es el 'fuerte', entonces la gente iba por él, incluso en busca de pelea mismo. Los otros grupos decían: 'vamos al grupo de fulano que es el grupo fuerte'. Y si el grupo venciese [el desafío de los visitantes], estaba bien, pero si lo perdiera, el nombre quedaba mal y ese grupo [el 'perdedor'] tendría que cambiar su nombre. (...) Si ganaba las peleas, estaba bien, el grupo quedaba conocido y a la vez temido por la gente (...). (Pantera. Madrid, noviembre/2007).

Estas visitas y desafíos también nos informan sobre la política de territorialidad que esas agrupaciones mantenían entre sí. Siguiendo a una división de los "territorios de actuación" de acuerdo con las "zona de influencia" de cada maestro, los grupos terminaban yuxtaponiendo el sentido de pertenencia colectiva a la ubicación espacial. Esta ubicación una calle, un barrio, un distrito, una favela, o una zona de la ciudad- funcionaría como parte de la iconografía grupal, situando "materialmente" la identidad que el gremio atribuía a sus integrantes.

Cuando decimos que la territorialización de los grupos era lo que les permitía una "ubicación material" de la identidad, aludimos a una interpretación del espacio que lo asume como el escenario donde las prácticas sociales se realizarán. Esa constatación nos acerca a una especie de paradoja del espacio relativa al hecho de que este sea, simultáneamente, una práctica social y el locus material de toda práctica social. Entre los capoeiristas, el reconocimiento del papel estructurante del espacio se confunde con su propia definición de especificidad grupal. Eso significa que los capoeiristas no solamente asumen el locus de ubicación (el territorio de actuación) como eje de su vida colectiva, como también asumen su vida colectiva (y su identidad grupal) como parte integrante del espacio al que "pertenecen". El espacio como práctica social se confunde con las prácticas sociales puestas en el espacio. Las identidades de los gremios de capoeiristas siempre explicitarán ese sentido paradójico de materialidad espacial y serán impensables desconectadas de su relación con un contexto local específico -lo que es verdad tanto para las agrupaciones de los años sesenta en las zonas periféricas de Río, como para aquellas que encontramos en Madrid en 2010-.

Esta apropiación de territorios es siempre una relación mediada por la figura del maestro. Eso equivale a decir que los maestros son indexados a un territorio que será reconocido como su "área de influencia" y que ese locus es "transferido" a los grupos que ellos coordinan:

"El Mestre Poeira plantó [la capoeira] en Padre Miguel. Si uno dice 'Padre Miguel', dice 'Mestre Poeira'. Pero si dicen 'en Copacabana', entonces ¿de quienes van a hablar? Van a hablar de [Mestre] Camisa. En Botafogo, van a hablar [Mestre] Peixinho. (...) En la Barra da Tijuca, ¿tú sabes de quien van a hablar? Hablan del 'Gilberto da Barra'. (Pantera. Madrid, enero/2010).

La relación territorio-maestro-grupo tiene dos consecuencias importantes para comprender el ímpetu migratorio de los capoeiristas de la generación de Pantera. En primer lugar, porque su "formación" en la capoeira (la asunción de la insignia de maestro) implicaba conseguir crear un territorio propio de acción: ganarse una zona, ser legítimamente asociado a un área y reconocido como "el maestro de allí". Eso conllevaba emanciparse del territorio del maestro de uno y buscar un nuevo espacio: la progresión en el mundo de la capoeira es indisociable de un sentido de expansión y apropiación de "territorios". En segundo lugar, porque la vinculación entre diferentes maestros resultaba en una relación entre diferentes territorios: si Mestre Poeira "es" Padre Miguel y Mestre Pantera "es" Madrid, entonces entre Madrid y Padre Miguel hay una interconexión 
porque esos dos maestros se comprendan como parte de una misma familia de capoeira. La reciprocidad relacional institucionalizada entre los maestros genera una vinculación al territorio que "comandan". Si la relación entre los maestros no es amistosa, habrá una rivalidad entre "territorios":

Yo empecé a dar clases en el Barata que es un barrio de Río, en el suburbio de Realengo (...) Yo daba clases ahí y fue cuando un tipo me vio y dijo: ‘¿capoeira aquí? ¡Yo imparto clases más allí adelante! Yo doy clases aquí'. Y yo le dije: 'ah, yo no lo sabía'. Ese tipo era el [Mestre] Paulão Dois de Ouro. No le gustó porque él no tenía buenas relaciones con Poeira. Él me preguntó: ‘¿tú eres alumno de quién?'. (Pantera. Madrid, diciembre/2009).

Como nos muestra la reacción de Paulão Dois de Ouro, el permiso de circulación en uno u otro territorio dependía de la afiliación a Poeira - un vínculo que ubicaba el joven Pantera en la capoeira suburbana de Río. No era lícito transitar en territorios de maestros rivales al suyo: ese tipo de movimiento podría terminar en peleas violentas. Tampoco era lícito impartir clases en un territorio que ya tuviese "dueño" y el joven capoeirista debería seguir buscando su espacio en áreas no indexadas a ningún maestro.

Esta función simbólica del territorio en la organización societaria de los gremios de capoeiristas es un elemento históricamente vinculante y se conecta al nacimiento de la práctica como una cultura callejera, como instrumento colectivo de apropiación del espacio público (Dias 2001; Holloway 1989; Graden 1996; Soares 2002). La "puesta en escena" de la capoeira comporta un sentido de ironía social, de "adueñarse de locus del otro" y de subvertir las grafías materiales del orden social que se materializan como el "orden del espacio" y como "el orden en el espacio". Sería inexacto afirmar que esos sentidos hayan permanecido intocados entre los capoeiristas, pero si es cierto asumir que la espacialidad que les es subyacente dejó su huella sus modos de agrupación colectiva. No es una casualidad que los maestros se refieran al movimiento de apropiación de territorios como un movimiento que "planta la historia": en el acto de cultivar la capoeira en otros locus sociales, los capoeiristas cultivan también una historicidad que transmite y expande esa relación subversiva, irónica y camuflada con el espacio. Podemos afirmar que esa "política de disputas" entre los más valientes constituía una política de territorialidad, de lucha por las zonas o áreas de influencia asumidas por un maestro y sus discípulos. Las disputas y la territorialización de las zonas de influencia eran parte del juego dinámico con el que las agrupaciones producían (activa y espacialmente) sus definiciones identitarias.

Esta circulación de los capoeiristas entre los territorios de los diferentes maestros implicaba una competencia para mantener la fidelidad de los alumnos. Tanto en las ruedas, como en las exhibiciones, los mestres y discípulos tenían su capoeira puesta a prueba constantemente. A la obligación de ser capaz de mantener una rueda de calle que fuera respetada y frecuentada por maestros importantes, se sumaba la obligación de conocer a las otras ruedas de la ciudad (frecuentándolas acompañado de sus discípulos). Ningún capoeirista que no conociera ese "circuito" de ruedas de Río sería legítimamente aclamado como Mestre. Con las ruedas en la calle, los grupos de la Zona Norte institucionalizan una forma propia de transitar por los diferentes territorios de los distintos barrios. Ese movimiento permitía que los capoeiristas de diferentes favelas se conocieran entre sí:

Yo conocí los mestres a través de Poeira y después con mi trabajo, porque ellos frecuentaban mi rueda. Conocí al Mestre Preguiça, conocí al Luís Malhado. Luis Malhado comandaba la rueda en Oaiba en el día 13 de mayo, día de los esclavos. Mestre Poeira también comandaba la rueda ahí [en Oaiba], pero comandaba más en Padre Miguel y en Bangú. El Mestre Roque, antiguo en la capoeira, daba clases en el IPCN, el Instituto de Investigación de la Cultura Negra, en la [calle] Mendes Sá, en el centro de la ciudad. Conocí el Mestre Vieira, del grupo Aidê, que da clases en Aguas Santas, conocí también al Mestre Martins. Conocí el Mestre Touro, muy famoso, muy conocido en Río, del grupo Corda Bamba. Conocí Mestre Dentinho, (...) que es del grupo Auê de 
Capoeira y daba clases en la Penha, dentro del Parque Shangai. Conocí otros mestres. Son muchos los mestres, ¿no? (...) Conocí el Mestre Artur Emídio, que era de la Zona Sur. De la periferia eran Mestre Roque y esos otros de los que yo estaba hablando, más el Mestre Dois de Ouro y el Mestre Mentirinha. (Pantera. Madrid, enero/2010).

Esas ruedas no se institucionalizaron solamente en los barrios periféricos, sino también en sitios del antiguo centro urbano: Largo da Carioca, Largo de Santa Rita, Praça 15, Cinelândia, Campo do Santana, Lapa, Central do Brasil, puntos que constituyen "lugares de memoria" para los capoeiristas cariocas (Travassos 2004:168): espacios donde la capoeira se escenificó desde fines del siglo XVIII, y que permanecieron en el imaginario de los capoeiristas rememorados por canciones, historias y mitos transmitidos de maestros a discípulos. Así, el "regreso" al centro carioca tuvo un especial sentido de historicidad alimentando la noción de una continuidad entre la capoeira practicada en el presente y el régimen de subordinación, violencia y explotación (Travassos 2004: nota 22) que contextualizó la criminalización del arte y su expulsión de la ciudad en el pasado.

\section{La rueda del Flamengo y el cruce de fronteras}

En la medida en que la capoeira se iba expandiendo en la Zona Norte, los maestros (sobre todo los más jóvenes que luchaban por ganarse territorios) empiezaron a organizar ruedas en las áreas nobles: los barrios de Flamengo, Copacabana, Leblon, Leme, Barra da Tijuca, Botafogo, Ipanema. La exposición pública del arte en estos espacios permitió que los jóvenes de las clases medias y alta viesen la capoeira de cerca, se fascinasen por su dinámica acrobática, por su plasticidad e ideales de virilidad masculina. Las ruedas se transformaron en la oportunidad para el contacto entre sujetos pertenecientes a dos mundos muy distintos: el maestro de la Zona Norte y el aspirante a discípulo de la Zona Sur. Poco a poco, esos maestros empiezan a penetrar en los barrios sureños: el encuentro en el locus urbano de los ricos generó la demanda por un nuevo tipo de profesional, "el profesor de capoeira":

(...) El Duda, que hoy es mi alumno formado, iba siempre al Flamengo y me dijo que siempre quedaba mirando la rueda de capoeira, allá en el Flamengo, la rueda que yo comandaba. Porque él quería aprender, pero no había encontrado un maestro [en la Zona Sur]. Entonces, cuando él me vio allá, cuando vio la forma de hacer las cosas que yo tenía, mi actitud con todo el mundo, que me daba igual, que no tenía miedo a nadie, entonces fue cuando él me preguntó y yo le dije: 'yo doy clases en el Cara de $B i^{l 1}$ '. Y él vivía en la [Calle] Barão de Tapagica, justo al lado del Colégio de Aplicação. (Pantera. Madrid, diciembre/2009).

Es el joven de la Zona Sur quien, valiéndose de contactos personales, consigue que Pantera empiece a dar clases en el prestigioso Colégio de Aplicação da UERJ ${ }^{12}$, en el barrio de Tijuca. La asociación de capoeira de Pantera cruza la frontera y emigra al otro mundo de Río: del norte al sur. Inicialmente, el maestro no quería que sus alumnos del "Cara de Boi" frecuentasen las clases allí:

Yo no quería mezclar los alumnos del Cara de Boi, que eran muchachos del morro. Pero yo les tenía que llevar para hacer la chispa. Entonces yo dije: 'vamos a hacer

${ }^{11}$ El "Cara de Boi" es como se denominaba popularmente un bloque de viviendas situado en la Tijuca, en el área cercana al distrito de Maracanã, y al barrio de Vila Isabel. Constituye un conjunto habitacional de familias con bajo poder adquisitivo.

${ }^{12}$ Instituto público de educación secundaria, administrado por la Universidad del Estado de Río de Janeiro. Pese a que sea público, el alumnado que acude al instituto es normalmente de clase media y media-alta. 
entrenamiento y rueda, entrenamiento y rueda'. Y entonces la gente del colegio empezó a ver y a querer hacerlo. Después yo continué y todo quedó mezclado y yo siempre decía en la clase: 'aquí en la capoeira no hay discriminación. Yo tengo alumno bandido, médico, policía, gente que no trabaja, quienes ganan mucho y quienes ganan poco. La capoeira es una. Eso es lo bueno del mundo de la capoeiragem. Porque si yo empiezo [a decir] 'capoeira es solo para médico, solo para policía y para abogado', entonces ustedes no se van a conocer. $\mathrm{Y}$ de repente, tu eres un abogado, estás dentro de un autobús y hay un asalto, y puede que alguno de los asaltantes también sea de la capoeira y diga: 'déjale que este es alumno del Pantera', y no te pasa nada, el asalto no acontece'. (Pantera. Madrid, enero/2010).

En el discurso de Pantera, notamos la articulación de una pretensión universalista ("la capoeira es una") que es una manifestación evidente de cómo su códice relacional inclusivo permite que la experiencia de pertenencia al colectivo sea una experiencia societaria que integra más allá de la diferencia de color de piel y condición económica. Innegablemente, ese traspaso de los grupos de capoeira hacia la Zona Sur inicia una experiencia de contacto entre mundos sociales que enriquece la capoeira, que introduce en ella una experiencia sui generis de alteridad, de convivencia entre diferentes, de mediación social (Conde 2008; Travassos 2004). En las clases y ruedas de Pantera, como en las de muchos maestros que en los años setenta implementaron sus grupos más allá de la Zona Norte, se genera un tejido social que interconecta diferentes realidades:

La gente que era abogado y estudiada [habían estudiado, los ricos] a veces hacían fiestas e invitaban: 'estoy haciendo una fiesta y todos están invitados'. Quien tenía buena ropa iba, quien tenía ropas malas, la gente de la favela que no tenía aquella ropa arreglada, iba también, pero eran todos tratados igualmente. (Pantera. Madrid, enero/2010).

Esa ruptura de fronteras sociales es fundamental por dos razones. En primer lugar porque son los jóvenes alumnos provenientes de las clases medias y ricas aquellos que podrán pagarle al maestro una mensualidad por las clases asistidas. Cobrando por las clases, el maestro podrá empezar a concebir la capoeira como una fuente de renta. Lógicamente, la existencia de alumnos que pagaban por su mensualidad no eliminó de la capoeira su espíritu de solidaridad en los márgenes de la sociedad: los alumnos de la periferia seguían sin pagar por las clases. Una diferenciación identitaria se dibujó entre los capoeiristas de la Zona Sur (que entrenaban en enormes instalaciones deportivas, contaban con uniformes nuevos, que solamente estudiaban y podían entrenar capoeira varios días de la semana) y los capoeiristas de la Zona Norte (que entrenaban en las calles o centros comunitarios improvisados, que trabajaban a jornada completa, que no podían costearse un pantalón de capoeira, y que jugaban por la noche, cuando el cuerpo cansado ya casi no les permitía el rigor del entrenamiento).

La segunda razón por la que la expansión de la capoeira a los barrios centrales representó una verdadera revolución en la práctica, se refiere al hecho de que ese movimiento introdujera la capoeira al locus social del que emanaban los valores que serían filtrados como hegemónicos en la sociedad. La Zona Sur de Río de Janeiro era la personificación espacial de la elite que producía los parámetros (gustos, hábitos, discursos, modas, formas de ser) que se convertirían en "lo natural" de la sociedad como un todo. La zona noble carioca era, en los años 1970 y 1980, el corazón de las modas que serían imitadas en todo el territorio nacional, y la presencia de la capoeira en aquél espacio legitimó la expansión y desarrollo de la práctica por todo el país.

Así, cuando la capoeira cruza la Zona Norte hacia la Zona Sur de la ciudad, los sujetos que la llevan en ese cruce, los capoeiristas, están en realidad emigrando de un país a otro, de un Brasil al otro Brasil. Una migración que era, antes de cualquier cosa, la mediación de las fronteras nacionales de la alteridad. Ese juego de cruce de fronteras se convirtió en el modus operandi de las agrupaciones en todo el Brasil, permitiendo a los capoeiristas de las 
favelas brasileñas proyectar un sueño migratorio que, más que cruzar las fronteras entre desarrollo y subdesarrollo en Brasil, lo hiciera a escala global.

\section{Bibliografía}

ABIB, P. R. J. (2006): "Os velhos capoeiras ensinam pegando na mão". Cadernos Cedes, 26 (68): 86-98.

ASSUNÇÃO, M.R. (2005): Capoeira. The history of an Afro-Brazilian martial art. Routledge. London - New York.

BRUHNS, H.T. (2000): Futebol, Carnaval e Capoeira. Entre as gingas do corpo brasileiro. - Papirus Editora. Campinas.

CARAMANO, A.A. y ABRAMOVAY, R. (1999): Exodo Rural, envelhecimento e masculinização no Brasil: Panorama dos últimos 50 anos. Textos para discussão $\mathrm{n}^{\circ}$ 621. IPEA. Rio de janeiro.

COMAROFF, J. y COMAROFF, J. (1992): Ethnography and the Historical Imagination. - Westview Press. Boulder-Colo.

CONDE, B.V. (2008): A arte da negociação: A capoeira como navegação social. Coleção Capoeira Viva. - Editora Novas Idéias. Rio de Janeiro.

DIAS, S. L. (2001): Quem tem medo de Capoeira? Rio de Janeiro 1890 - 1904. Secretaria Municipal das Culturas. Rio de Janeiro.

FABIAN, J. (2007): Memory against Culture. Arguments and Reminders. - Duke University Press. Durham y Londres.

FARIA, C. (2005): Revolucionários, bandidos e Marginais. Presos Políticos e comuns sob a Ditadura Militar. Tese de Maestria, defendida en el Programa de Pós-graduação em História (PPGH) de la Universidade Federal Fluminense (UFF), Niterói. http://colunistas.ig.com.br/luisnassif/files/2009/11/Dissert_MACHADO_Catia_Conceicao Faria.pdf (enero/2012)

FLORY, T. (1977): "Race and Social Control in Independent Brazil." Journal of Latin American Studies 9(2): 199-224.

GOLDSTEIN, D.M (2009): "Perils of Witnessing and Ambivalence of Writing: Whiteness, Sexuality, and Violence in Rio de Janeiro Shantytowns" en Woman Fieldind Danger. Negotiating Ethnographic Identities in Field Research. Huggins, M.K.; Glebbeek, M.L. (eds.) - Rowman \& Littlefield Publishers. Lanham, Boulder, Nueva York, Toronto y Plymouth.

GRADEN, D.T. (1996): "An Act 'Even of Public Security': Slave Resistance, Social Tensions, and the End of the International Slave Trade to Brazil, 1835-1856." The Hispanic American Historical Review, 76(2): 249-282.

GUIZARDI, M. L. (2011): "Genuinamente brasileña". La nacionalización y expansión de la capoeira como práctica social en Brasil. Araucaria: Revista Iberoamericana de filosofia, politica y humanidades, 26: 72-100.

HETHERINGTON, K. (1996): "Identity Formation, Space and Social Centrality." Theory, culture \& society: explorations in critical social science, 13(4): 31-52.

HOLLOWAY, T.H. (1989): "A Healthy Terror': Police Repression of Capoeiras in Nineteenth-Century Rio de Janeiro." The Hispanic American Historical Review, 69(4): 637-676.

LEEDS, A. y LEEDS, E. (1978): A Sociologia do Brasil Urbano. - Zahar Editores. Rio de Janeiro.

LEWIS, John Lowell,

(1992): Rings of Liberation: deceptive discourse in Brazilian Capoeira. - University of Chicago Press. Chicago-London.

(1995):"Genre and Embodiment. From Brazilian Capoeira to an Ethnology of human movement”. Cultural Anthropology, 10: 221-243. 
(1999): "Sex and Violence in Brazil. Carnaval, capoeira and the problem of everyday life". American Ethnologist, 26 (3): 539-557.

MAUSS, Marcel

(1979a): "Las técnicas del cuerpo, en Sociología y Antropología, MAUSS, M. Tecnos.Madrid.

(1979b): "Ensayo sobre los dones. Motivo y forma del cambio en las sociedades primitivas", en Sociología y Antropología, MAUSS, M. - Tecnos.Madrid: 155-258.

MERRELL, F. (2005): Capoeira and Candomble: conformity and resistence through Afro-Brazilian Experience. - Markus Wiener Publisher. Princeton.

ORTIZ, R. (2003): Cultura Brasileira e Identidade Nacional. - Brasiliense. São Paulo.

PAZ, E.A. (1987): As pastorinhas de Realengo. - UFRJ-PROED. Rio de Janeiro.

PERLMAN, J.E.

(2002): Marginality: From Myth to Reality in the Favelas of Rio de Janeiro 1969-2002. Mega-Cities Project/Trinity College. World Bank Urban Symposium.

(2008): "Caminos esquivos para salir de la pobreza. Movilidad intra e intergeneracional em las favelas de Río de Janeiro", en, Salir de la pobreza. Perspectivas interdisciplinares sobre la movilidad social, Narayan, D. y Petesch, P. (Ed.). - Mayol Ediciones. Banco Mundial: 225-268.

SANTOS, M. (2008): A urbanização brasileira. - EDUSP. São Paulo.

SOARES, C.E.L. (2002): A Capoeira escrava e outras tradições rebeldes no Rio de Janeiro (1808 - 1850). - Editora Unicamp. Campinas.

STEPHENS, N. y DELAMONT, S. (2006): "Samba no mar: Bodies, Movement and Idiom in Capoeira", en, Body/embodiment: symbolic interaction and the sociology of the body._Waskul, D.D. y Vannini, P. -Ashgate Publishers. Farnham.

TRAVASSOS, S.D. (2004): "Capoeira e alteridade. Sobre mediações, trânsitos e fronteiras", en Um século na favela, Zaluar, A.; Alvito, M. (org.). - Editora de la Fundação Getúlio Vargas. Rio de Janeiro: 167-180.

VIANA, C.G. de A.(2010): "Realengo e a escola militar: um estudo sobre memória e patrimônio urbano". Revista Mosaico: História, Política e Bens Culturais-FGV, 1(2) http://cpdoc.fgv.br/mosaico/?q=artigo/realengo-e-escola-militar-um-estudo-sobre-mem \%C3\%B3ria-e-patrim\%C3\%B4nio-urbano (enero/2012). 